\title{
Self Efficacy Scale For People With Drug Abuse Disorders
}

\author{
Agus Supriyanto ${ }^{1}$, Nurlita Hendiani ${ }^{2}$ \\ Fakultas Keguruan dan Ilmu Pendidikan, Universitas Ahmad Dahlan \\ Yogyakarta ${ }^{1}$, Balai Besar Rehabilitasi, Badan Narkotika Nasional ${ }^{2}$ \\ Email: agus.supriyanto@bk.uad.ac.id ${ }^{1}$,nurlitahen@gmail.com²
}

\begin{abstract}
:
Intent to influence the process of recovery and relapse prevention for people with Substance Abuse Disorders (GPZ), which is being rehabilitated. The purpose of the study was to find the dimension of self-efficacy people with GPZ to recover from drug addiction, as well as valid and reliable statement items on self-efficacy scale instruments. This study used a mixed methods approach with the transformative sequential design. Instrument research through documentation studies, interviews, and surveys with $N=217$. Qualitative descriptive analysis through the study of journal and book, focus group discussion for the determination of the statement items. Quantitative descriptive analysis to know the validity and reliability of the instrument. The findings reveal indicators of self-efficacy scales to recover from addiction through three dimensions, ie (1) level dimension, (2) general dimension, and (3) strength dimension. The self-efficacy scale has 32 valid statements with a coefficient of Corrected Item-Total Correlation $\geq 0148$ and has a reliability coefficient of 0.862 with a high category. Self-efficacy scales are useful identifying confidence levels for people's with GPZ during rehabilitation programs and counseling development.
\end{abstract}

Keyword: Self Efficacy, Addiction, Drugs Rehabilitation

Received February 23, 2018; Revised March 20, 2018; Accepted April 01, 2018

How to Cite: Supriyanto A., \& Hendiani N. (2018). Self Efficacy Scale For People With Drug Abuse Disorders. JKI (Jurnal Konseling Indonesia), 3(2), 57-63.

\section{PENDAHULUAN}

Narkoba atau narkotika, psikotropika, dan zat adiktif berbahaya bagi tubuh manusia. Semakin besar dampak dan gejala pada individu, semakin banyak penanggulagan terhadap jenis perilaku (Arcidiacono et al., 2010). Obat-obatan terlarang tidak pernah jauh dari pandangan media dan meskipun diidentifikasi hampir satu dekade yang lalu sebagai 'medan pertempuran baru' untuk bidang alkohol dan obat lain (Lancaster, Hughes, Spicer, MATTHEW - SIMMONS, \& Dillon, 2011). Obat-obatan terlarang memiliki efek samping yang berbahaya bagi kesehatan (Vidar Hanstad \& Waddington, 2009), penurunan kinerja akademis mahasiswa (Arria et al., 2013), status kesehatan mental yang buruk (Grinman et al., 2010), hubungan dagang, implikasi ekonomi, dan dampaknya terhadap pandemik global (Nsimba, 2009). Hasil penelitian menjelaskan bahwa adanya hubungan antara faktor impulsif dan penyalahgunaan obat lain, seperti jenis kelamin, status 
hormonal, reaktivitas terhadap penghargaan obat-obatan, dan pengalaman lingkungan awal yang dapat mempengaruhi asupan obat selama semua fase kecanduan (Perry \& Carroll, 2008).

Fakta menunjukkan bahwa relaps pada orang dengan Gangguan Penyalahgunaan Zat (GPZ) yang sedang menjalani program rehabilitasi. Relapse merupakan jatuh kembali ke pola perilaku awal (Reber \& Reber, 2010). Pengobatan yang diberikan di pusat rehabilitasi sebagian besar peserta memiliki niat yang sangat rendah untuk sembuh (Lian \& Chu, 2013). Kecanduan narkoba memiliki resiko terhadap psikologis individu. Tiga faktor risiko psikologis adalah self efficacy, harapan hasil yang menguntungkan, dan sifat impulsif tinggi (Wu, Cheung, $\mathrm{Ku}, \&$ Hung, 2013). Efikasi diri diperoleh, dikembangkan, atau diturunkan melalui salah satu atau kombinasi dari empat sumber, yaitu (1) mastery experience, (2) social modelling, (3) persuasi verbal dan sosial, dan (4) kondisi fisik dan emosi. Efikasi diri (Feist \& Feist, 2008). Efikasi diri individu juga nampak pada tiga dimensi, yaitu level, strength, dan generality (Bandura, 1997).

Rehabilitasi narkoba merupakan upaya pemulihan yang dilaksanakan konselor untuk membantu orang dengan GPZ untuk pulih dari kecanduan. (Myrick, 1987), rehabilitation counselors offer a wide range of services to people with physical, emotional, and/or developmental disabilities. Rehabilitasi menjadi kebutuhan yang mendesak akan kebijakan obat berbasis bukti yang menghormati hak orang-orang yang menggunakan narkoba dan berusaha memperbaiki kesehatan pengguna (Fu, Bazazi, Altice, Mohamed, \& Kamarulzaman, 2012).

Pelayanan yang diberikan konselor untuk membantu pemulihan psikis, emosi, dan perkembangan potensi klien. Preferensi identitas yang terkait dengan self-efficacy sebagai strategi untuk mengurangi kekambuhan pada individu yang memiliki perilaku adiktif (Buckingham, Frings, \& Albery, 2013). Posttraumatic growth pecandu narkoba berkaitan dengan emotion focused coping, positive reappraisal, acceptance, dan denial (Nurlita \& Agus, n.d.).

Kondisi yang diharapkan dari rehabilitasi adalah keyakinan untuk sembuh dari kecanduan narkoba. Efikasi diri pecandu narkoba untuk pulih dari kecanduan pada masa rehabilitasi perlu diketahui untuk pencegahan relaps dan keyakinan untuk pulih. Tujuan utama efikasi diri adalah pengembangan fungsi kognitif dalam program rehabilitasi neurokognitif yang diimplementasikan sebagai bagian dari pengobatan kecanduan (Rezapour, DeVito, Sofuoglu, \& Ekhtiari, 2016). Penggunaan assessment yang tepat, relevan, valid, dan reliable akan sangat mendukung pada proses pelaksanaan dari pendekatan bimbingan maupun konseling bagi orang dengan GPZ yang menjalani program rehabilitasi narkoba (Supriyanto, 2017).

Keyakinan diri orang dengan GPZ yang sedang menjalani program rehabilitasi narkoba menjadi penentu untuk sembuh dari kecanduan narkoba dan pencegahan relaps. Keyakinan diri orang dengan GPZ perlu diukur untuk mengetahui tingkat efikasi diri dan segera disadari oleh konselor, penyelenggara program rehabilitasi narkoba, dan keluarga orang dengan GPZ. Instrumen yang dapat dikembangkan berupa skala efikasi diri. Skala efikasi diri berguna sebagai assessment untuk mengetahui tingkat efikasi diri orang dengan GPZ yang sedang menjalani program rehabilitasi narkoba dan dapat diimplementasikan sebagai alat ukur. Hasil penelitian ini memaparkan tentang proses penyusunan instrumen skala efikasi diri valid dan reliabel yang sesuai konsep dan aplikasinya. Penggunaan instrumen juga memperhatikan tujuan instrument, salah satunya mengukur perubahan (Lord, Corsello, \& Grzadzinski, 2014). Hasil penelitian ini berguna agar skala yang layak untuk mengetahui tingkat efikasi diri orang dengan GPZ yang sedang menjalani pemulihan dari kecanduan narkoba pada program rehabilitasi.

\section{METODE PENELITIAN}

Penelitian ini menggunakan pendekatan mixed methods. Rancangan penelitian menggunakan rancangan transformatif sekuensial. Hasil penelitian memiliki tujuan untuk menemukan butir-butir pernyataan yang valid dan reliabel pada instrumen skala efikasi diri.

Intrument penelitian ini melalui studi dokumentasi beruapa analisis teks, wawancara, dan survei. Rancangan penelitian dalam pendekatan mixed methods melalui enam tahap. Pertama, tahap studi literatur di jurnal dan buku ilmiah. Kedua, wawancara penyusunan butir-butir pernyataan melalui forum group discussion (FGD). Ketiga, wawancara mengenai butir-butir pernyataan terhadap ahli dan subyek penelitian. Keempat, pengembangan item pernyataan sesuai aspek. Kelima, survei hasil pengembangan item pernyataan sesuai aspek. Terakhir, menguji validitas dan reliabilitas.

Tahap pertama, menemukan dimensi efikasi diri melalui studi literatur melalui analisis jurnal dan buku ilmiah yang memuat dimensi efikasi diri untuk sembuh dari kecanduan narkoba. Tahap kedua, forum group discussion (FGD) dengan pakar/ ahli. Hasil temuan FGD menemukan indikator efikasi diri dari dimensi efikasi dan penyusunan butir-butir pernyataan. Tahap ketiga, butir-butir pernyataan divalidasi oleh dua ahli dan dua praktisi (konselor adiksi) untuk mengetahui validitas isi dari butir-butir pernyataan pada dimensi 
efikasi diri. Tahap keempat, pengembangan 40 butir-butir efikasi diri. Tahap kelima, survei untuk uji coba butir-butir efkasi diri pada 217 orang dengan GPZ yang sedang menjalani program rehabilitasi di Balai Besar Rehabilitasi, Badan Narkotika Nasional di Indonesia. Tahap keenam, hasil survei dianalisis untuk mengetahui validitas dan reliabilitas instrument melalui rumus korelasi product moment untuk menentukan tingkat validitasnya dan rumus alpha cronbach untuk menentukan tingkat reliabilitasnya. Hasil temuan akan menunjukkan data tentang dimensi efikasi diri dan item-item yang valid dan reliabel untuk dapat mengukur efikasi diri untuk sembuh dari kecanduan narkoba.

Analisis penelitian menggunakan analisis deskriptif kualitatif tentang kajian jurnal dan buku sebagai studi dokumentasi, focus group dicussion penentuan butir-butir pernyataan, dan hasil validasi ahli dan praktisi (konselor adiksi) tentang isi dari butir-butir pernyataan. Analisis dalam penelitian juga menggunakan analisis deskriptif kuantitatif dari hasil uji beda untuk mengetahui validitas dan reliabilitas instrumen efikasi diri. Hasil analisis akan menemukan fakta tentang dimensi, indikator, dan butir-butir pernyataan dari efikasi diri untuk sembuh dari kecanduan narkoba dengan subjek adalah orang dengan GPZ yang sedang menjalani program rehabilitasi narkoba.

\section{HASIL}

Hasil temuan dari studi literatur melalui analisis jurnal dan buku ilmiah menjadi rujukan utama untuk mengetahui efikasi diri. Efikasi diri juga tentang keyakinan dalam kemampuan seseorang untuk mengatur dan melaksanakan program tindakan yang diperlukan untuk mengelola situasi prospektif (Bandura, 1995). Efikasi diri diperoleh, dikembangkan, atau diturunkan melalui salah satu atau kombinasi dari empat sumber, yaitu (1) mastery experience, (2) social modelling, (3) persuasi verbal dan sosial, dan (4) kondisi fisik dan emosi. Efikasi diri (Feist \& Feist, 2008). Efikasi diri individu juga nampak pada tiga dimensi, yaitu level, strength, dan generality (Bandura, 1997). Temuan dari studi literatur mengungkap dimensi level, strength, dan generality sebagai panduan penyusunan kisi-kisi instrument skala efikasi diri dan item pernyataan.

Tabel 1. Dimensi Efikasi Diri

\begin{tabular}{|c|c|l|}
\hline $\begin{array}{c}\text { N } \\
\text { o }\end{array}$ & $\begin{array}{c}\text { Dimensi } \\
\text { Efikasi } \\
\text { Diri }\end{array}$ & \\
\hline 1. & Level & $\begin{array}{l}\text { a. Merasa yakin dirinya mampu mengerahkan usaha untuk dapat melakukan rehabilitasi } \\
\text { dengan baik } \\
\text { b. Merasa yakin dirinya mampu menghasilkan output untuk mencapai kesembuhan. } \\
\text { c. Merasa yakin individu mampu menghadapi tantangan yang ada } \\
\text { d. Merasa yakin dirinya memiliki cara untuk dapat menyelesaikan rehabilitasi } \\
\text { e. Merasa yakin dirinya mampu melakukan rehabilitasi dengan tepat waktu. }\end{array}$ \\
\hline 2. & Generalit & $\begin{array}{l}\text { a. Merasa yakin mampu melakukan rehabilitasi yang mampu diselesaikan orang lain. } \\
\text { b. Merasa yakin dapat menyelesaikan rehabilitasi dengan menggunakan kognisi, afeksi, } \\
\text { dan psikomotorik. } \\
\text { c. Merasa yakin terhadap kemampuan dalam menyelesaikan rehabilitasi dengan } \\
\text { karakterisik diri sendiri }\end{array}$ \\
\hline 3 & Strength & $\begin{array}{l}\text { a. } \text { Gigih dalam mencapai kesembuhan } \\
\text { b. Merasa yakin bahwa tindakan yang dipilih akan akan mencapai kesembuhan }\end{array}$ \\
\hline
\end{tabular}

Temuan butir pernyataan diperoleh dari focus group discussion (FGD) dengan ahli dan konselor adiksi. Focus group method memiliki tujuan dan harapan untuk memberikan kepastian bahwa tidak ada jawaban 'benar' atau 'salah' dan untuk mengurangi kekhawatiran akan justifikasi (Plummer, 2017), serta pengembangan wawasan dan pemahaman tentang fenomena tertentu (Gill, Stewart, Treasure, \& Chadwick, 2008). Temuan selanjutnya dalam penelitian ini adalah butir-butir pernyataan dari dimensi efikasi diri. Hasil validasi isi dari praktisi dan ahli menemukan indikator efikasi diri dan 40 butir pernyataan untuk mengungkap tiga dimensi efikasi diri. Indikator Efikasi diri yaitu (1) dimensi tingkat meliputi indikator yakin akan usaha dalam program rehabilitasi, yakin akan hasil dari program rehablitasi, yakin akan hambatan, yakin untuk menyelesaikan program rehabilitasi, dan yakin akan kemampuan melakukan rehabilitasi, (2) dimensi general meliputi membandingkan dirinya dengan orang lain untuk menyelesaikan program rehabilitasi, yakin akan aspek kognisi, afeksi, dan psikomotorik, dan yakin akan kemampuan diri untuk menyelesaikan program rehabilitasi, serta (3) dimensi kekuatan meliputi indikator kegigihan untuk 
sembuh, dan yakin akan tindakan untuk sembuh dari kecanduan narkoba. Butir-butir pernyataan sesuai dengan perkembangan psikologis orang dengan GPZ yang sedang menjalani program rehabilitasi narkoba.

Item pernyataan dalam skala efikasi diri yang telah disusun diuji coba dengan $\mathrm{N}=217$ responden (orang dengan GPZ yang mengikuti program rehabilitasi narkoba). Uji validitas dan reliabilitas skala efikasi diri dibantu dengan aplikasi SPSS 19. Hasil analisis korelasi product moment dapat disimpulkan bahwa dari 40 jumlah total item pernyataan efikasi diri, 32 item diataranya dinyatakan valid, sehingga 32 item dipertahankan dan 8 item dinyatakan gugur, dengan koefisien nilai Corrected Item-Total Correlation $\geq$ 0.148. Hasil analisis Alpha Cronbach, koefisien reliabilitas instrumen skala efikasi diri adalah 0,862 yang termasuk dalam kategori reliabilitas tinggi. Hasil temuan menjadi dasar bagi instrumen skala efikasi diri layak untuk digunakan untuk mengetahui tingkat efikasi diri untuk sembuh dari kecanduan narkoba. Validitas dan reliabilitas untuk menyediakan instrumen yang valid dan data empiris (Csikszentmihalyi \& Larson, 2014).

Tabel 2. Pernyataan Dimensi Tingkat

\begin{tabular}{|l|c|}
\hline \multicolumn{1}{|c|}{ Tingkat } & $\begin{array}{c}\text { Corrected Item } \\
\text { Total Correlation }\end{array}$ \\
\hline $\begin{array}{l}\text { Saya mencari tahu informasi tentang kecanduan narkoba pada konselor/ staf } \\
(+)\end{array}$ &, 169 \\
\hline Saya konsultasi masalah kecanduan yang saya alami (+) &, 168 \\
\hline $\begin{array}{l}\text { Saya mampu menghindari hal-hal yang mendorong saya memakai narkoba } \\
\text { kembali. }(+)\end{array}$ &, 225 \\
\hline Saya mempunyai rencana ke depan dalam menjalani rehabilitasi. (+) &, 188 \\
\hline Saya mampu mengatasi kebosanan dalam menjalani rehabilitasi. (+) &, 129 \\
\hline $\begin{array}{l}\text { Ketika orang lain mampu menyelesaikan program rehabilitasi, saya juga dapat } \\
\text { melakukannya. }(+)\end{array}$ &, 168 \\
\hline $\begin{array}{l}\text { Ketika teman lain mampu mengerjakan tugas dari konselor/ staf, saya juga } \\
\text { dapat mengerjakannya. }(+)\end{array}$ &, 173 \\
\hline
\end{tabular}

Tabel 3. Pernyataan Dimensi Kekuatan

\begin{tabular}{|l|c|}
\hline \multicolumn{1}{|c|}{\begin{tabular}{c}
\multicolumn{1}{|c|}{$\begin{array}{c}\text { Dimensi Kekuatan } \\
(+/-)\end{array}$} \\
Program rehabilitasi ini mengajarkan saya bebas dari narkoba
\end{tabular}} & $\begin{array}{c}\text { Corrected Item } \\
\text { Total Correlation }\end{array}$ \\
\hline $\begin{array}{l}\text { Karena penerimaan diri saya yang baik saya mampu menjalani program } \\
\text { rehabilitasi. }\end{array}$ &, 159 \\
\hline $\begin{array}{l}\text { Ketika saya melakukan kesalahan saat program rehabilitasi, saya tahu } \\
\text { bagaimana caranya untuk memperbaikinya. }\end{array}$ &, 159 \\
\hline $\begin{array}{l}\text { Saya berusaha mencari kelebihan dan kelemahan diri saya, supaya tidak } \\
\text { terjerumus dalam narkoba }\end{array}$ &, 522 \\
\hline Saya telah tahu cara menolak ajakan teman untuk memakai narkoba &, 400 \\
\hline $\begin{array}{l}\text { Saya yakin rencana yang saya buat setelah dari rehabilitasi ini akan membantu } \\
\text { menjaga pemulihan diri saya }\end{array}$ &, 518 \\
\hline Saya acuh tak acuh dengan masalah kecanduan saya &, 529 \\
\hline Saya merasa tidak ada masalah dengan kecanduan. &, 494 \\
\hline Sulit bagi saya untuk menjalani program rehabilitasi &, 552 \\
\hline Kerapkali saya tidak dapat mengendalikan emosi. &, 521 \\
\hline Saya takut tidak bisa menolak ajakan memakai narkoba. &, 392 \\
\hline Saya tidak bisa mengidentifikasi faktor pemicu pemakaian narkoba. &, 561 \\
\hline
\end{tabular}

Tabel 4. Pernyataan Dimensi Generality

\begin{tabular}{|l|c|}
\hline \multicolumn{1}{|c|}{ Dimensi General } & $\begin{array}{c}\text { Corrected Item } \\
\text { Total Correlation }\end{array}$ \\
\hline Saya tidak tahu tujuan program rehabilitasi ini. &, 540 \\
\hline Seringkali saya bosan dan malas menjalani program rehabilitasi. &, 314 \\
\hline Tugas yang diberikan konselor tidak penting bagi saya. &, 548 \\
\hline Saya merasa kesusahan menjalani program rehabilitasi. &, 606 \\
\hline
\end{tabular}




\begin{tabular}{|l|c|}
\hline $\begin{array}{l}\text { Saya pikir ada teman saya yang kambuh/ relapse, meskipun sudah menjalani } \\
\text { program rehabilitasi dengan baik. }\end{array}$ &, 385 \\
\hline Program rehabilitasi tidaklah penting karena masih ada yang relapse/kambuh. &, 554 \\
\hline Saya merasa program rehabilitasi ini tidak membantu pemulihan. &, 494 \\
\hline Saya pesimis dapat pulih dari penyakit narkoba ini. &, 525 \\
\hline $\begin{array}{l}\text { Program rehabilitasi ini tidak sesuai dengan karakter diri saya yang susah } \\
\text { diatur. }\end{array}$ &, 420 \\
\hline Saya menolak melakukan perubahan dalam diri saya. &, 440 \\
\hline Ketika saya mendapat pembelajaran saya tidak tahu harus berbuat apa. &, 585 \\
\hline Saya takut menghadapi dunia luar setalah keluar dari rehabilitasi ini &, 489 \\
\hline $\begin{array}{l}\text { Setelah keluar dari rehabilitasi, saya hanya akan mengurangi dosis pemakaian } \\
\text { saya. }\end{array}$ &, 572 \\
\hline
\end{tabular}

\section{PEMBAHASAN}

Layaknya penelitian (Orford, Velleman, Natera, Templeton, \& Copello, 2013) menyatakan bahwa individu yang kecanduan menjadi kelompok tanpa suara kolektif yang menyebabkan turunnya efikasi diri untuk sembuh. (Anggraini, Wahyuni, \& Soejanto, 2017) menjelaskan bahwa efikasi diri memiliki keterkaitan dengan reseliensi. Penelitian lain (Negus \& Miller, 2014), data efikasi diri dapat digunakan untuk menentukan potensi penyalahgunaan relatif dari berbagai obat. Harapanya, penggunaan assessment yang tepat, relevan, valid, dan reliabel akan sangat mendukung pada proses pelaksanaan dari pendekatan bimbingan maupun konseling untuk sembuh dari kecanduan narkoba (Supriyanto, 2017).

Skala efikasi diri dapat digunakan untuk mengukur tingkat efikasi diri orang dengan GPZ untuk pulih dan sedang menjalani program rehabilitasi. Tingkat efikasi diri dari skala efikasi diri menjadi dasar untuk menyusun rencana tindakan guna mencegah relaps dan sembuh dari kecanduan narkoba. Rencana tersebut akan tertuang dalam program rehabilitasi yang memandu konselor adiksi dalam memberikan bimbingan dan konseling pada orang dengan GPZ. Fungsi utama adalah sebuah deteksi dan intervensi (Chen, Storr, \& Anthony, 2009), serta terapi individual (Romão, Canhão, \& Fonseca, 2013). Problematika terkait narkoba memerlukan pelayanan konseling (Eickhoff, Hämmerlein, Griese, \& Schulz, 2012) dan bimbingan Islam yang diimplementasikan dengan format klasik, format kelompok, dan format individu untuk mengembangkan mental (Supriyanto, 2017). Penggunaan gaya komunikasi motivasional daripada konfrontatif selama konseling, penting untuk memperbaiki hasil pasien (Shapiro, Coffa, \& McCance-Katz, 2013).

Skala efikasi diri yang telah dikembangkan diharapkan dapat digunakan konselor adiksi ataupun peneliti untuk mengidentifikasi efikasi diri untuk sembuh dari kecanduan narkoba. Konselor dapat merancang sebuah strategi konseling untuk mengembangkan efikasi diri dan mencegah relaps. Informasi dari klien berkaitan hasil konseling memiliki korelasi positif untuk membangun hubungan anta konselor dan klien (Geller, Greenberg, \& Watson, 2010).

\section{SIMPULAN DAN SARAN}

Butir-butir pernyataan yang valid dan reliabel pada instrumen skala efikasi diri disusun melalui tiga dimensi, yaitu dimensi level, dimensi generality, dan, dan dimensi kekuatan. Dimensi tingkat memiliki indikator-indikator yaitu yakin akan usaha dalam program rehabilitasi, yakin akan hasil dari program rehablitasi, yakin akan hambatan, yakin untuk menyelesaikan program rehabilitasi, dan yakin akan kemampuan melakukan rehabilitasi. Dimensi general memiliki indikator-indikator yaitu membandingkan dirinya dengan orang lain untuk menyelesaikan program rehabilitasi, yakin akan aspek kognisi, afeksi, dan psikomotorik, dan yakin akan kemampuan diri untuk menyelesaikan program rehabilitasi. Dimensi kekuatan memiliki indikator-indikator yaitu kegigihan untuk sembuh, dan yakin akan tindakan untuk sembuh dari kecanduan narkoba. Butir-butir pernyataan pada skala efikasi diri sesuai dengan perkembangan psikologis orang dengan GPZ yang sedang menjalani program rehabilitasi narkoba.

Skala efikasi diri memiliki 32 butir pernyataan yang valid, dengan koefisien nilai Corrected Item-Total Correlation $\geq 0.148$. Koefisien reliabilitas skala efikasi diri adalah 0,862 yang termasuk dalam kategori reliabilitas tinggi. Hasil temuan berupa skala efikasi diri dapat digunakan oleh konselor adiksi atau peneliti 
untuk mengidentifikasi tingkat efikasi diri untuk sembuh dari kecanduan narkoba dan merancang sebuah strategi konseling untuk mengembangkan efikasi diri, serta strategi mencegah relaps.

\section{DAFTAR RUJUKAN}

Anggraini, O. D., Wahyuni, E. N., \& Soejanto, L. T. (2017). Hubungan antara Efikasi Diri dengan Resiliensi Menghadapi Ujian pada Siswa Kelas XII SMAN 1 Trawas. JKI (Jurnal Konseling Indonesia), 2(2), $50-56$.

Arcidiacono, C., Velleman, R., Procentese, F., Berti, P., Albanesi, C., Sommantico, M., \& Copello, A. (2010). Italian families living with relatives with alcohol or drugs problems. Drugs: Education, Prevention and Policy, 17(6), 659-680.

Arria, A. M., Wilcox, H. C., Caldeira, K. M., Vincent, K. B., Garnier-Dykstra, L. M., \& O’Grady, K. E. (2013). Dispelling the myth of "smart drugs": Cannabis and alcohol use problems predict nonmedical use of prescription stimulants for studying. Addictive Behaviors, 38(3), 1643-1650.

Bandura, A. (1995). Self-efficacy in changing societies. Cambridge university press.

Bandura, A. (1997). Self-efficacy: The exercise of control. Macmillan.

Buckingham, S. A., Frings, D., \& Albery, I. P. (2013). Group membership and social identity in addiction recovery. Psychology of Addictive Behaviors, 27(4), 1132.

Chen, C.-Y., Storr, C. L., \& Anthony, J. C. (2009). Early-onset drug use and risk for drug dependence problems. Addictive Behaviors, 34(3), 319-322.

Csikszentmihalyi, M., \& Larson, R. (2014). Validity and reliability of the experience-sampling method. In Flow and the foundations of positive psychology (pp. 35-54). Springer.

Eickhoff, C., Hämmerlein, A., Griese, N., \& Schulz, M. (2012). Nature and frequency of drug-related problems in self-medication (over-the-counter drugs) in daily community pharmacy practice in Germany. Pharmacoepidemiology and Drug Safety, 21(3), 254-260.

Feist, J., \& Feist, G. J. (2008). Theory of personality. Alih Bahasa [2006]. Santoso. Yogyakarta: Pustaka Pelajar.

Fu, J. J., Bazazi, A. R., Altice, F. L., Mohamed, M. N., \& Kamarulzaman, A. (2012). Absence of antiretroviral therapy and other risk factors for morbidity and mortality in Malaysian compulsory drug detention and rehabilitation centers. PloS One, 7(9), e44249.

Geller, S. M., Greenberg, L. S., \& Watson, J. C. (2010). Therapist and client perceptions of therapeutic presence: The development of a measure. Psychotherapy Research, 20(5), 599-610.

Gill, P., Stewart, K., Treasure, E., \& Chadwick, B. (2008). Methods of data collection in qualitative research: interviews and focus groups. British Dental Journal, 204(6), 291.

Grinman, M. N., Chiu, S., Redelmeier, D. A., Levinson, W., Kiss, A., Tolomiczenko, G., ... Hwang, S. W. (2010). Drug problems among homeless individuals in Toronto, Canada: prevalence, drugs of choice, and relation to health status. BMC Public Health, 10(1), 94.

Lancaster, K., Hughes, C. E., Spicer, B., MATTHEW-SIMMONS, F., \& Dillon, P. (2011). Illicit drugs and the media: Models of media effects for use in drug policy research. Drug and Alcohol Review, 30(4), $397-402$.

Lian, T. C., \& Chu, F. Y. (2013). A qualitative study on drug abuse relapse in Malaysia: contributory factors and treatment effectiveness. International Journal of Collaborative Research on Internal Medicine \& Public Health, 5(4), 217-232.

Lord, C., Corsello, C., \& Grzadzinski, R. (2014). Diagnostic instruments in autistic spectrum disorders. Handbook of Autism and Pervasive Developmental Disorders, Fourth Edition.

Myrick, R. D. (1987). Developmental guidance and counseling: A practical approach. ERIC.

Negus, S. S., \& Miller, L. L. (2014). Intracranial self-stimulation to evaluate abuse potential of drugs. Pharmacological Reviews, 66(3), 869-917.

Nsimba, S. E. D. (2009). Problems associated with substandard and counterfeit drugs in developing countries: A review article on global implications of counterfeit drugs in the era of anti-retroviral (ARVS) drugs in a free market economy.

Nurlita, H., \& Agus, S. (n.d.). POSTTRAUMATIC GROWTH PADA PECANDU NARKOBA (Landasan Pengembangan Program Konseling Pecandu Narkoba pada Proses Rehabilitasi). In Prosiding Seminar Nasional Konseling Krisis.

Orford, J., Velleman, R., Natera, G., Templeton, L., \& Copello, A. (2013). Addiction in the family is a major but neglected contributor to the global burden of adult ill-health. Social Science \& Medicine, 78, 7077. 
Perry, J. L., \& Carroll, M. E. (2008). The role of impulsive behavior in drug abuse. Psychopharmacology, 200(1), 1-26.

Plummer, P. (2017). Focus group methodology. Part 2: Considerations for analysis. International Journal of Therapy And Rehabilitation, 24(8), 345-351.

Reber, A. S., \& Reber, E. S. (2010). Kamus Psikologi. Yogyakarta: Pustaka Pelajar.

Rezapour, T., DeVito, E. E., Sofuoglu, M., \& Ekhtiari, H. (2016). Perspectives on neurocognitive rehabilitation as an adjunct treatment for addictive disorders: from cognitive improvement to relapse prevention. In Progress in brain research (Vol. 224, pp. 345-369). Elsevier.

Romão, V. C., Canhão, H., \& Fonseca, J. E. (2013). Old drugs, old problems: where do we stand in prediction of rheumatoid arthritis responsiveness to methotrexate and other synthetic DMARDs? BMC Medicine, 11(1), 17.

Shapiro, B., Coffa, D., \& McCance-Katz, E. F. (2013). A primary care approach to substance misuse. Am Fam Physician, 88(2), 113-121.

Supriyanto, A. (2017). Rehabilitation Counseling: Concept Assessment Guidance and Counseling For Drugs Abuse. In Prosiding Seminar Bimbingan dan Konseling (Vol. 1, pp. 19-30).

Vidar Hanstad, D., \& Waddington, I. (2009). Sport, health and drugs: a critical re-examination of some key issues and problems. Perspectives in Public Health, 129(4), 174-182.

Wu, A. M. S., Cheung, V. I., Ku, L., \& Hung, E. P. W. (2013). Psychological risk factors of addiction to social networking sites among Chinese smartphone users. Journal of Behavioral Addictions, 2(3), 160166. 